\title{
Las corporaciones locales y las comunidades de vecinos ante los retos de la nueva gestión pública ${ }^{1}$
}

\author{
Vicente María González-Haba Guisado \\ Secretario de Administración Local, categoría superior
}

SUMARIO: I. EL PORQUÉ DE LA NUEVA GESTIÓN PÚBLICA. II. CARACTERÍSTICAS DE LA NUEVA FUNCIÓN PÚBLICA. III. LAS CORPORACIONES LOCALES. IV. LAS COMUNIDADES DE VECINOS. BIBLIOGRAFÍA UTILIZADA.

\section{EL PORQUÉ DE LA NUEVA GESTIÓN PÚBLICA}

Como dice la doctrina, la aplicación del concepto de gestión al sector público es relativamente reciente (Olías DE Lima GeTE), ya que el mismo, tradicionalmente, ha sido patrimonio del sector privado. Todos sabemos que en el área de las Administraciones el término tradicional ha sido, valga la redundancia, el de «administrar».

¿Qué diferencias hay entre «administrar» y «gestionar»? Diríamos que «administrar» es simplemente utilizar y manejar todo aquello que tenemos a nuestro alcance (medios humanos, materiales, económicos, tecnológicos, etc.); y, por el contrario, «gestionar» tiene un sentido más agresivo, más dinamizador, más inconformista, más participativo. Siguiendo a la autora antes citada, el buen administrador es el que se limita a combinar eficientemente recursos predeterminados para alcanzar fines que le vienen dados, mientras que el buen gestor es el que, además de hacer lo acabado de indicar, se dedica a buscar nuevos medios para alcanzar los objetivos propuestos impulsado por una legítima ambición de mejorar los resultados de la organización. Y si, en concreto, nos fijamos en el factor humano de las organizaciones, entonces las diferencias entre ambos conceptos se acentúan porque el administrador es el que se limita a considerar a los empleados como «un recurso más o menos limitado e inamovible», mientras que el gestor los considera como «un elemento esencial de la organización»; y, en consecuencia, trata de extraer de ellos el máximo rendimiento, inculcarles una intensa motivación en la realización y ejecución de sus tareas, e identificarlos con las metas y las finalidades de la organización a la que pertenecen.

\footnotetext{
${ }^{1}$ Este trabajo es el texto, debidamente adaptado para su publicación, de la conferencia prevista para ser pronunciada por el autor en la Casa de Cultura de Santoña (Cantabria) el 11 de junio de 2003.
} 
Aclarados los dos conceptos, «administrar» y gestionar», la primera parte de este trabajo está dedicada a justificar y razonar por qué, en las sociedades de nuestro tiempo, la gestión ha venido a reemplazar, y en cierto modo a sustituir, a la administración propiamente dicha. Las causas de este cambio son múltiples, diversas y de muy heterogénea naturaleza. Veamos brevemente algunas de ellas que nos ayuden a comprender esta transformación esencial que se ha producido, y se está produciendo en estos momentos en todas las Administraciones Públicas, y, por tanto, también en la Administración Local.

1) Hemos de citar, en primer término, lo que se ha dado en llamar «la crisis del Estado del Bienestar», propio de los países democráticos del Occidente europeo, y entre los que se encuentra España. Ante el crecimiento de las demandas por parte de los ciudadanos y grupos sociales, y ante la escasez de recursos con los que los Estados deben hacer frente a aquéllas, no hay más alternativa que poner freno al expansionismo incontrolado del Estado, y reducir no sólo el repertorio de sus funciones y actividades sino el mismo tamaño del Estado en cuanto tal. De ahí el eslogan tan habitual en nuestros días, y que patrocinan muchos administrativistas y sociólogos, de «menos Estado pero mejor Estado». Y de ahí también arrancan, podríamos decir, todos los procesos de privatización, liberalización, desregulación, etc., de los que tanto se habla actualmente en los medios de comunicación social.

2) En segundo lugar, hemos de tener presente la concienciación, cada vez más intensa, que sienten los ciudadanos, los vecinos, los usuarios de servicios públicos, que pagan religiosamente sus impuestos; y, que, con razón, se creen en el legítimo derecho de exigir de autoridades y funcionarios que cumplan sus compromisos electorales, que utilicen con eficacia y rectitud los formidables medios que tienen a su disposición, que los presupuestos de gastos reviertan en actuaciones reflejadas en mejores hospitales, mejores escuelas, mejores carreteras, mejores playas, mejores instalaciones de ocio, mejores servicios de seguridad ciudadana, etc.

3) En tercer lugar, hay que aludir a los nuevos retos derivados de las grandes innovaciones tecnológicas de nuestros días y que, bien utilizadas, propiciarán una gran «revolución» en el modo de actuar y comportarse el Estado y las Administraciones Públicas. La incorporación de medios técnicos, electrónicos y telemáticos al aparato político y administrativo determina que éste, de un lado, deba readaptarse continuamente a los nuevos desafíos de la ciencia y de la técnica para no quedar obsoleto; y, de otro, que tenga que mejorar sus canales de relación con el ciudadano para que éste se sienta satisfecho en sus reivindicaciones, se sienta partícipe y soli- 
dario con las decisiones de quienes le gobiernan, y se sienta, en definitiva, inmerso, y no desplazado, en la gestión de la cosa pública.

Es ahora el momento oportuno para decir que debemos cuestionar esa concepción, tan de moda hoy y muy aireada por algunos, de que «el ciudadano es un cliente de la Administración». A mi juicio, estamos ante un enfoque desviado y equívoco si se le interpreta al pie de la letra, sin hacer las debidas matizaciones, porque parece como si estuviéramos moviéndonos en el plano de las relaciones que existen entre el individuo y un gran centro comercial, pongamos por caso. Personalmente hablando, nunca me he sentido cliente del Estado, o de mi Comunidad Autónoma, o de mi Ayuntamiento. Más bien, por el contrario, me quiero reconocer «miembro» de éstos, «titular» de derechos y obligaciones, «partícipe» de las instituciones públicas en las que, por una razón u otra, estoy directamente implicado como ciudadano, como vecino, como usuario; y, en ningún caso, quiero comportarme como un «cliente» que se limita a comprar y pagar. Aceptar esta visión de las cosas en virtud de la cual el ciudadano es pura y simplemente un «cliente», sería tanto como rebajar nuestra ciudadanía, nuestra vecindad, nuestra personalidad a límites inaceptables de renuncia de nuestros deberes cívicos y de abdicación de nuestros derechos políticos y administrativos.

Quizás, todo hay que decirlo, esta concepción del ciudadano como «cliente» sea la que deseen algunos impulsar para, de esta forma, «apoderarse» del Estado y de la Administración, alejando al hombre de la calle, al ciudadano, al administrado, con intenciones no demasiado limpias, y más bien interesadas y dirigidas a dejar en manos de burócratas distanciados de la realidad social la gestión y dirección de los asuntos públicos que, en principio y por definición, a todos nos incumben.

4) En cuarto lugar, hay que citar como otra causa del cambio antes enunciado la preocupación acelerada por la idea de calidad. Pocas palabras tan en boga en nuestros días como la de la calidad de los servicios y las prestaciones. Hoy el ciudadano ya no se conforma con que tan sólo se le proporcionen servicios y prestaciones de cualquier nivel o valor, sino que postula y exige que tanto unos como otras sean de calidad, consecuentes con los avances de la ciencia y las nuevas tecnologías, acordes con las cotas de progreso de la sociedad en que vive. Y no sólo se habla de calidad a secas, sino que la meta a conseguir hoy es ya más elevada, porque se pretende alcanzar nada menos eso que se denomina la «calidad total». Por ello, no debe sorprendernos que se haya llegado a decir que la calidad total viene a ser algo así como «la idea movilizadora del cambio» tanto en el terreno empresarial como en el público. 
5) Y, en quinto lugar, debemos dedicar unas líneas a la idea, prevalente en la actualidad, de la eficacia. Hasta tal punto es así que no faltan administrativistas que sostienen que la Administración Pública se legitima básicamente por la eficacia que demuestra en sus actos y decisiones. Todo lo que es eficaz es válido, se dice o al menos se piensa, y lo que no es eficaz no es válido. Tal planteamiento, llevado hasta sus últimas consecuencias, es inadecuado y no puede asumirse sin más. Por muy omnipresente y todopoderoso que sea esa especie de nuevo dios de la modernidad, que es la eficacia, tenemos que tener presente que, al menos en el plano de lo público, la eficacia tiene siempre un límite infranqueable como es el respeto a la ley y a los derechos de las personas y los individuos. La eficacia, pues, debe doblegarse a los imperativos de la legalidad, pero también hay que añadir, a renglón seguido, que la legalidad no está (pese a lo que, a veces, se piensa, si observamos ciertas normas desafortunadas e impropias del siglo en que vivimos) para torpedear la eficacia y el dinamismo de las instituciones públicas sino, por el contrario, para evitar abusos de poder y promover en cada uno de nosotros el pacífico ejercicio de nuestros derechos y libertades.

\section{CARACTERÍSTICAS DE LA NUEVA FUNCIÓN PÚBLICA}

Esbozadas con brevedad las causas que han conducido el tránsito desde la «administración» hasta la «gestión», como nueva idea-eje del comportamiento de la Administración, se trata ahora de explicar cuáles son las principales características o rasgos de la Nueva Gestión Pública que, poco a poco, se abre camino por todas partes; y que, como reza el título de este trabajo, supone un gran reto tanto para las Administraciones Públicas (en nuestro caso, aquí y ahora, las Corporaciones Locales) como para los ciudadanos (es decir, las Comunidades de Vecinos de nuestros pueblos y ciudades).

La doctrina, ciertamente, no se pone muy de acuerdo a la hora de acotar el concepto de «Nueva Gestión Pública» (o, en siglas tan de moda hoy, NGP), porque se trata de un concepto borroso, difuminado y de fronteras y límites imprecisos, que empezó a utilizarse hacia los años noventa. De una manera genérica, a mi juicio, la Nueva Gestión Pública podría ser definida como «el conjunto de principios y técnicas que, procedentes de la gestión o management privado, se tratan de aplicar por las organizaciones públicas para que éstas, dentro de las peculiaridades que las caracterizan, realicen y cumplan con eficacia los objetivos que les son propuestos desde las instancias políticas competentes para ello». 
Lo primero que hemos de subrayar al respecto es que, por mucho que pretendamos asimilar las organizaciones públicas a las privadas, hay que aceptar que existen notables diferencias entre unas y otras, entre la gestión pública y la gestión privada, entre el modo de dirigir una empresa y el modo de conducir un Ayuntamiento; y que, por tanto, impiden una identificación plena entre ambos ámbitos de acción. Por lo mismo, no debe extrañarnos que los autores se hayan encargado de apuntar las «peculiaridades» de la gestión pública, y que recuerden con insistencia que hay profundas diferencias entre el Gerente de una gran industria y el Alcalde de un Ayuntamiento, lo que determina que no pueda realizarse un trasvase incondicional y pleno de las técnicas y aportaciones del management privado al sector público.

A título puramente enunciativo, y por ello no exhaustivo, con BAUZÁ Martorell, que a su vez cita al profesor GiBert, podemos recordar las siguientes diferencias entre gestión pública y gestión privada:

a) Las organizaciones públicas tienen, por lo general, mayor dimensión que las privadas y cuentan con una estructura territorial y funcional difícil de ajustar y sincronizar en todas sus piezas y elementos.

b) Las organizaciones públicas inspiran su actividad de servicio a los ciudadanos en el interés general, que es muy diferente del ánimo de lucro y maximización de beneficios que preside el funcionamiento de la empresa privada.

c) Al igual que en el sector privado, en el público los recursos disponibles son limitados. Sin embargo, la diferencia en materia de financiación radica en que en la actuación pública los recursos se consignan presupuestariamente, afectados a una partida de gasto y aprobados por ley, lo que impide o dificulta aplicar la técnica de la planificación, dados los obstáculos legales para alterar el destino y montante de las partidas presupuestarias por la vía de las correspondientes modificaciones.

d) Las organizaciones públicas articulan su funcionamiento en torno a un sistema jurídico, básicamente el Derecho administrativo, que se orienta muchas veces más a la protección del ciudadano frente al poder que a velar por la gestión de los servicios públicos o por el logro de las metas deseadas por los ciudadanos.

e) Finalmente, las organizaciones públicas están sometidas al poder político y su toma de decisiones se encuentra muy condicionada por motivos de oportunidad (los programas electorales de los partidos, con motivo 
de las recientes elecciones locales y autonómicas, son buen ejemplo de ello).

Otros autores de la importancia de SuBIRATs añaden nuevas «peculiaridades» como son:

f) Las organizaciones públicas no escogen su ámbito de actuación, sino que éste les viene impuesto legal o estatutariamente, a diferencia del sector privado que se sitúa libremente donde ve mayores posibilidades de obtener beneficios.

g) Las organizaciones públicas tienen instrumentos coercitivos y sancionadores, de los que carecen las entidades privadas.

h) Las organizaciones públicas se insertan en un contexto más complejo y variado que el de las privadas, por lo que su necesidad de acudir a la negociación y la transacción es mayor a la hora de afrontar los problemas y proponer fórmulas adecuadas de solución.

i) En las organizaciones públicas la determinación de objetivos es mucho más ambigua, intangible y confusa que en las privadas, por lo que resulta mucho más difícil evaluar o medir el rendimiento de los órganos y las personas que los persiguen.

j) Por último, en las organizaciones públicas la gestión de los recursos humanos y financieros es más complicada que en las privadas debido a factores diversos, desde el momento en que dicha gestión, que va desde la selección hasta la separación del servicio pasando por la promoción profesional, se encuentra sometida a formalidades muy estrictas desde el punto de vista legal o reglamentario; lo que igualmente sucede con el manejo de los recursos dinerarios o económicos en los que las formalidades para su disposición son igualmente estrictas y rígidas.

Las «peculiaridades» de la gestión pública, acabadas de exponer, señalan con claridad que no cabe una identificación plena y total entre la Administración y la empresa privada a la hora de gestionar sus intereses y realizar sus cometidos. Por tanto, pretender trasladar en bloque las técnicas de gestión privada del sector privado al público es una mal planteamiento que conviene superar. No obstante, a renglón seguido, conviene añadir que las diferencias expuestas tampoco pueden ser excusa suficiente para que determinadas técnicas del sector privado sean aplicadas en el ámbito público a fin de mejorarlo, desarrollarlo y rentabilizarlo. 
Si nos atenemos a los hechos, y pese a la distancia existente entre lo público y lo privado como se acaba de demostrar, debemos reconocer que la Nueva Gestión Pública, si se quiere con matices y cautelas, se está abriendo paso en el seno de las Administraciones Públicas de Occidente y, también en las de nuestro país. Esta aceptación tiene su plasmación en una serie de puntos que tanto la doctrina más consolidada como prestigiosos autores se vienen encargando de defender y difundir, y como ha expuesto, entre otros, TERMEs Anglés en un trabajo sobre los «Principios que inspiran la reforma del sector público alrededor del mundo» y que, para este autor, son los que siguen:

a) Principio de privatización y contractualización, de manera que todas las actividades que puedan ser desarrolladas por el sector privado no deben ser asumidas por el sector público. Aquí cabe citar la conocida frase de OSBORNe y GaEbleR de que «nadie puede remar y al mismo tiempo llevar el timón, y el Estado tampoco puede hacerlo». En otras palabras, al Estado le toca llevar el timón (o sea, marcar objetivos, procurar la eficiencia, asignar recursos, controlar la marcha de la embarcación, etc.), pero son otros (es decir, la sociedad, los ciudadanos) los que deben remar.

b) Principio de modernización o corporatización, en virtud del cual los grandes sistemas operativos que, por su medida llegan a un elevado grado de complejidad, deben ser sustituidos por subsistemas más pequeños, más ágiles, más flexibles y también más efectivos. Ésta es la tendencia universal a crear agencias, entes autónomos, centros o unidades de decisión, etc., que descarguen a la respectiva Administración de funciones que pueden ser llevadas a cabo por organismos de ella dependientes y dotados de suficiente autonomía, flexibilidad y elasticidad para adaptarse a cada situación.

c) Principio de programación política y ejecución gerencial, lo que viene a significar que, en las sociedades modernas, al político le corresponde marcar las estrategias y objetivos, mientras que el gestor profesional, bajo el lema de la eficacia, está llamado a desarrollar la táctica aplicable en cada caso y a lograr materialmente los objetivos seleccionados por el político.

d) Principio de descentralización, que, de alguna manera, se corresponde con el de subsidiariedad, y que busca trasladar las competencias desde los niveles administrativos más altos a los más próximos al ciudadano; de ahí que hoy se hable tanto del «principio de proximidad». Este principio, como es lógico, es de gran trascendencia en la Administración Local, porque lo que ésta pueda hacer no lo deberían hacer ni la Administración esta- 
tal ni la autonómica. Sucede, sin embargo, que cuando estos temas se plantean apostando decididamente por una Administración Local firme y fuerte, bien asentada política y administrativamente, surgen los que alguien ha denominado «los nuevos jacobinos», es decir, los nuevos centralistas, que no quieren unas Corporaciones Locales dotadas de verdadera autonomía porque su ideología les lleva a defender más bien la dependencia de los Ayuntamientos antes del Estado, y ahora de las Comunidades Autónomas.

e) Principio de eficiencia y eficacia, puesto que la Administración, como cualquier organización, debe actuar con arreglo a estos dos parámetros presentes en todo tipo de organizaciones. Es erróneo pensar que una Administración, cualquiera que sea, puede desenvolverse fuera de dichos parámetros, como también lo es sostener que éstos no se pueden predicar de las organizaciones públicas en cuanto que se han de guiar por otro tipo de criterios. Lo uno no está reñido con lo otro, y una buena Administración Pública tiene que tener presentes los principios citados, para no incurrir en la irresponsabilidad, el despilfarro, el abuso, a la hora de disponer de los muchos medios que los ciudadanos ponen en sus manos.

f) Principio de rendición de cuentas y de control, porque el gestor público no se debe colocar, como sucede con frecuencia, por encima del bien y del mal, sino que, al igual que en el sector privado, debe, de una parte, rendir cuentas ante quienes le han autorizado o antes quienes le han encomendado alguna misión; $y$, de otra, ha de someterse al control correspondiente para comprobar el grado de cumplimiento de los objetivos propuestos y, si hubiere alguna anomalía, tratar de averiguar las causas exigiendo en su caso las correspondientes responsabilidades políticas, contables, disciplinarias, penales, etc.

g) Principio de simplicidad administrativa, para que las normas sean lo menos complicadas posibles y se redacten de modo asequible al ciudadano; para que los procedimientos administrativos sean menos complicados y más sencillos, eliminando papeles innecesarios, actuaciones duplicadas, molestias superfluas, trámites interminables; y para que los organigramas sean transparentes, ligeros, descargados de toda duplicidad orgánica o funcional.

h) Principio de colaboración sector público-sector privado, desde el instante en que la línea de separación de ambos sectores se torna cada vez menos clara, abriéndose continuamente nuevas puertas de aproximación de colaboración y entendimiento. En nuestros días, como dice SHERRING, «el Gobierno está demasiado lejos del pueblo, es necesario, por tanto, que se acerque». Y este acercamiento debe hacerlo a través de las muchas orga- 
nizaciones que existen en los Estados, como son los colegios profesionales, las universidades, las organizaciones no gubernamentales, las asociaciones vecinales, etc., llamadas a servir de cauce para intercambio de propuestas e iniciativas entre lo público y lo privado.

i) Finalmente, el principio de innovación, porque la Administración, como cualquier quehacer humano, debe renovarse continuamente y más en los tiempos que corren en los que, como dice TeRMEs ANGLÉs, «los cambios constantes de la economía, la tecnología, la percepción de la sensibilidad pública, etc., no permiten hoy las posiciones estáticas»; añadiendo este autor que «la innovación constante es la antítesis del gobierno estático» y, en definitiva, con arreglo a la afirmación aparentemente desmesurada de LINDQUIST, «debemos crear la oportunidad de pensar lo impensable». En definitiva, tenemos derecho a pensar que a la velocidad con que hoy se mueven las sociedades modernas en todas las direcciones (económica, sanitaria, industrial, medioambiental, política, cultural), lo que ahora nos parece irrealizable, o quizás imposible, acabará siendo realidad tal vez a la vuelta de la esquina, como vulgarmente se dice.

Todos los principios acabados de exponer nos ayudan a enmarcar lo que hoy debemos entender por Nueva Gestión Pública. Evidentemente proclamar estos principios es fácil, pero lo complicado, y lo más arduo, es convertirlos en hechos contantes y sonantes. Ésta y no otra es la causa de que muchas reformas administrativas, de que muchos proyectos de modernización del sector público, tanto en el extranjero como entre nosotros, hayan naufragado y tan sólo se han reflejado en los Boletines de las Cámaras o los Diarios Oficiales, al faltarles el respaldo de una verdadera voluntad política para gestarlos, culminarlos y aplicarlos hasta sus últimas consecuencias.

\section{LAS CORPORACIONES LOCALES}

Toca ahora abordar las relaciones de la Nueva Gestión Pública con las Corporaciones Locales, sin perjuicio de incidir después sobre la problemática de las Comunidades de Vecinos. Hay que hacer hincapié, especialmente, en esta dualidad indisoluble Corporaciones Locales-Comunidades de Vecinos, porque siendo preciso que, con arreglo a las tendencias y orientaciones ya descritas, se reformen nuestras Corporaciones Locales, también deberán seguir el mismo camino las Comunidades de Vecinos, ya que poco se podrá hacer de interesante y renovador en el ámbito local si las autoridades locales (Alcaldes, Concejales, Presidentes de Diputación, Diputados Provinciales, Alcaldes Pedáneos, etc.) no cuentan con la cola- 
boración y el apoyo de los ciudadanos; o si éstos se limitan a mantener actitudes pasivas, inerciales y en ningún caso entusiastas y renovadoras.

Desde el punto de vista de las Corporaciones Locales, es evidente que hoy asistimos a una revitalización de lo que se ha dado en llamar Gobiernos Locales. En este sentido es válida la tesis de quienes sostienen que, en España, de los tres niveles en que se escalona el Estado (central, autonómico y regional) el que, sin duda, más se ha caracterizado por su espíritu de cambio y puesta al día de las estructuras político-administrativas, por la implantación de políticas públicas originales y avanzadas, por la tenacidad en resolver problemas básicos de la colectividad, ha sido la Administración Local. Y ello ha sucedido pese a los muchos obstáculos que se han alzado en el camino, desde la carencia de medios económicos hasta el recelo de las Comunidades Autónomas y del propio Estado, y que de alguna manera, directa o indirectamente, siguen minando o torpedeando muchas veces el protagonismo necesario de las Diputaciones Provinciales $\mathrm{y}$, sobre todo, de los Ayuntamientos.

Conviene recordar que, en nuestro país, a estas alturas todavía hay muchos que no acaban de entender y comprender el ser y la razón de ser del mundo local. Todavía hay quienes siguen mirando al pasado, rememorando el modelo decimonónico francés para el que «los municipios —en frase de Quim BRUGUÉ y Ricard Gomá- aparecen como entes privados, asociaciones dedicadas a defender sus propios intereses, pero sin que en ningún caso comporten la potestad del Estado central para intervenir en asuntos de interés general». Cierto que tanto «los municipios franceses, como los españoles, han transformado su naturaleza jurídica y se han convertido en entes de Derecho público — añaden los autores citados-, pero no se han liberado de una herencia que, con ventajas e inconvenientes, les convertía en representantes de algo tan poco político como sus propios intereses. Y ésta es la razón principal de la desconfianza que despiertan en las instituciones políticas centrales». Y todavía hay quienes, basándose en el modelo anglosajón, consideran al municipio como entidad prestadora de servicios a las «órdenes» de las instancias centrales del poder (es la tradición anglosajona del mal llamado selfgovernment).

Ambas líneas de pensamiento, principalmente la francesa pero también, aunque con menor grado de influencia, la anglosajona, tratan de recortar el papel del municipio y de obscurecer su dimensión política y social en el marco global del Estado. Sin embargo, los hechos son más fuertes que las teorías y, en la realidad con la que nos enfrentamos cada día, la gran verdad es que la Administración Local, y más explícitamente los municipios, son la apuesta del futuro y adquieren un protagonismo cada vez más inten- 
so en la vida pública no sólo, como tradicionalmente se cree, en el plano administrativo sino también ideológico y político.

Esta última afirmación, la de que el municipio se convierte en un crisol de acción política, ideológica y, además si se quiere pero en el buen sentido de la palabra, partidista, se despliega en varias direcciones que quisiera brevemente analizar e interpretar desde mi óptica personal, es decir, tal como yo veo e interpreto los acontecimientos que discurren a nuestro alrededor.

1) Primeramente, y pese a que estamos insertos en lo que se llama el fenómeno de la globalización (alguien ha dicho que el mundo se ha convertido en lo que se denomina «aldea global» y que vivimos en la «era global»), hoy asistimos por contraposición a la reivindicación en todas partes de lo local, de lo municipal, de lo particular. «Sabemos — afirma DAHRENFORF- que la globalización es intrínsecamente una tendencia ambigua, dual, en la cual la gente es atraída hacia el más vasto mundo, pero también hacia el consuelo del vecino más cercano. La globalización ha producido, pues, un refuerzo hacia el localismo, una aspiración a llevar las decisiones a ese nivel». Está de moda, pues, el localismo frente al estatalismo y frente a la mundialización de las relaciones sociales. Se comprende entonces lo que un sociólogo francés, Daniel BeLl, ha dicho cuando, con referencia a las estructuras en las que se configura el mundo actual, afirma que el Estado-nación es demasiado pequeño para resolver los grandes problemas de la vida, y demasiado grande para resolver los pequeños problemas de cada día. Ésta es la causa de que el hombre se vuelva a lo local, a lo suyo, a lo inmediato; y en este regreso hacia lo propio, hacia lo que más cerca tiene, trata de encontrar su identidad y su justificación como hombre, como persona y como ciudadano.

2) En segundo lugar, comprobamos cómo en nuestro país la Administración Local no solamente ve ampliarse y ensancharse sus áreas de influencia administrativa, sino que, además y ello es importante subrayarlo, va recuperando un sentido político propiamente dicho del que antes carecía. De ahí que, cada vez con más insistencia, se hable y escriba no sólo de la Administración Local sino también, escrito con mayúscula, de Gobierno Local; es decir, ya no sólo tenemos Administración Local, término neutral y aséptico, sino que también tenemos Gobierno Local que es una expresión de mayor significado y, por tanto, muy a tener en cuenta dado su alcance y contenido. Nuestra Constitución, aunque algunos lo olviden con frecuencia, en su artículo 140 establece que «el gobierno y administración de los municipios corresponde a los Ayuntamientos», con lo que el constituyente nos está dando una buena pauta sobre lo que deben ser y hacer los Ayuntamientos. Pese a que el Tribunal Constitucional en 
una de sus primeras sentencias sostuvo que la autonomía local era de carácter administrativo frente a la de las Comunidades Autónomas que era de naturaleza política, y por lo tanto cualitativamente superior, un amplio sector de la doctrina ha criticado este planteamiento del alto Tribunal y sostiene que los municipios gozan de autonomía política, además de la administrativa, en orden a gozar de la capacidad para orientar su actividad según los principios y postulados ideológicos que consideren más convenientes a los intereses y demandas vecinales. Aunque las Corporaciones Locales no gocen de la potestad legislativa, que para algunos parece ser el signo distintivo entre autonomía política y administrativa, sin embargo, conviene no olvidar que los Ayuntamientos están formados por Concejales elegidos democráticamente, los cuales, dentro de varias opciones políticas, pueden elegir la que consideren más adecuada y con arreglo a ella diseñar su actuación corporativa desde la elaboración del presupuesto hasta la implementación de las políticas públicas locales.

Conviene insistir en este punto de la autonomía no sólo administrativa sino también política de los Ayuntamientos españoles, porque, en los años venideros, ésta será la gran cuestión a dilucidar. Y de ella va a depender en gran medida que los Ayuntamientos rompan los tradicionales moldes de su encorsetamiento administrativo, y empiecen a hacer política en el buen sentido de la palabra, ofreciendo a los vecinos alternativas o programas de acuerdo con el ideario de cada grupo, partido o formación.

3) En tercer lugar, conectando con la primera parte de este trabajo, las Corporaciones Locales han de someterse a un proceso de reforma y modernización, siguiendo las orientaciones de la Nueva Gestión Pública, dentro de las coordenadas propias y características de la Administración Local, a través de lo que hoy se denomina «políticas públicas locales»; y cuyas notas más destacadas podemos sintetizar de la forma siguiente:

a) Las políticas locales, a diferencia de las estatales y autonómicas, van dirigidas a promover la gestión de prestaciones que se hacen a los vecinos de una manera directa, inmediata y presencial.

b) En relación con lo acabado de indicar, dichas prestaciones han de ser debidamente diferenciadas y segmentadas según el tipo de destinatarios a las que van dirigidas (personas sin recursos, marginados, discapacitados, tercera edad, jóvenes, parados, inmigrantes, colectivos específicos o singularizados por circunstancias diversas, etc.)

c) Las prestaciones que llevan a cabo los Ayuntamientos son más personalizadas e individualizadas que las que proceden de otros centros o ins- 
tancias de decisión, puesto que las Entidades Locales están más próximas al ciudadano y, en este sentido, se sitúan en mejores condiciones para responder a sus necesidades y peticiones de ayuda.

d) Estas mismas prestaciones, muchas veces, se concretan en actuaciones que constituyen, por decirlo de alguna forma, «el trabajo sucio» de la acción pública, el lado menos agradecido y espectacular de la gestión pública, como es el caso, por ejemplo, de la limpieza de las calles, la atención a los indigentes, el control de los alimentos y bebidas, la regulación del tráfico, etc. Como escribe SubIRATs, en este sentido la labor de las autoridades locales siempre es más ingrata y, por supuesto, «mucho menos brillante que la del ejecutivo central (política exterior,...) o la de los gobiernos regionales (política universitaria,...)», haciéndose directamente responsable a cada Ayuntamiento de los cometidos citados, «mientras en tareas más «macro» de otros niveles de gobierno, la responsabilidad es más difusa o no existe»; y con el agravante añadido de que, muchas veces, las tareas que pesan sobre los municipios no son totalmente asumidas por los poderes locales «dada la fragmentación de poderes y competencias en que se trabaja, y la gran dependencia de recursos del gobierno local respecto de otros poderes del sistema».

e) Las prestaciones municipales, a la hora de ser aprobadas o determinadas por los órganos representativos del municipio, ofrecen asimismo la dificultad que apunta SUBIRATs de que dichos órganos están sometidos a la presión diaria y cercana tanto de los propios vecinos como de los partidos políticos, los grupos de interés, los diputados regionales, los diputados nacionales, los Ministros, etc. «Todo ello — concluye el autor citadoconfigura un sistema de representación política débil».

f) Finalmente, las prestaciones locales resultan cada vez más difíciles de administrar y otorgar, dado que, en su realización y financiación, intervienen otros poderes que desbordan incluso las fronteras nacionales, como es el caso de los poderes comunitarios a través de los Fondos Estructurales y de Cohesión. Aquí radica la importancia, cada vez más reconocida y aceptada, de las llamadas relaciones interadministrativas de colaboración, cooperación y coordinación, y sin olvidar las de control o fiscalización; y sin las cuales es difícil, por no decir imposible, que funcione el Estado compuesto que es el Estado de las Autonomías, dentro del cual hay multitud de piezas integrantes de un gran engranaje y que, para que actúen correctamente y no bloqueen el funcionamiento de todo el sistema, precisan de mecanismos impulsores de unas buenas relaciones entre las tres Administraciones que existen en nuestro país, y a las que hay que adicionar la de la Unión Europea. Es éste, conviene indicarlo aquí, uno de los 
grandes problemas de nuestro Estado autonómico en el momento presente, ya que, pensando tan sólo en nuestros Ayuntamientos, es fácil vaticinar que no podrán funcionar eficazmente si sus relaciones con las otras Administraciones están cortocircuitadas o carecen de la necesaria fluidez a la hora de tomar decisiones importantes, firmar convenios o acuerdos, financiar conjuntamente prestaciones o servicios, etc.

Por lo que concierne a las transformaciones de las Corporaciones Locales, pensando en el horizonte en que se han de desenvolver en los próximos años y partiendo de las características acabadas de exponer sobre las políticas públicas locales, podemos pronosticar el cuadro de cambios que se avecinan, si interpretamos los signos de los tiempos que descubrimos por todas partes y que nos hablan de localismo administrativo, la hora de las ciudades, la gobernabilidad local, la gestión por proximidad, el gerencialismo local, el municipalismo relacional, el pacto local, la Administración receptiva, la eficacia democrática, términos todos ellos que demuestran propósitos de cambio y anuncian reformas muy profundas en la vida local española. Veámoslas brevemente a continuación.

1) En primer lugar, todo el tema de la participación ciudadana en su conjunto está hoy sometido a revisión. Así, Jordi BoRJA ha afirmado que «la participación de los ciudadanos en la vida local se ha convertido en uno de grandes temas políticos de nuestra época». Los cauces actuales participativos en el ámbito local son insuficientes y buena prueba de ello la encontramos en que son cada vez más los Ayuntamientos que abren nuevas vías a la participación ciudadana, partiendo del artículo 1. ${ }^{\circ}$ de la Ley de Bases de Régimen Local según el cual «los municipios son entidades básicas de la organización territorial del Estado y cauces inmediatos de participación ciudadana en los asuntos públicos», mientras que el artículo $18 .^{\circ}$ señala, entre los derechos de los vecinos, el de «participar en la gestión municipal, de acuerdo con lo dispuestos por las leyes».

Algunos Ayuntamientos se han mostrado pioneros en esta materia de la participación. Podemos citar, siguiendo a RUEDA Gómez, el Ayuntamiento de Granada que, como muchos otros Ayuntamientos democráticos, especialmente los que estuvieron gobernados por la izquierda, desde la legislatura 1979-1983 empezó a regular la participación implantando diversos mecanismos, superando diferentes etapas que culminaron con la aprobación del Reglamento Municipal de Información y Participación Ciudadana en la tercera legislatura de 1987-1991, y su desarrollo posterior a través de la Comisión Mixta de Descentralización y Participación Ciudadana de 27 de octubre de 1989, y de la Comisión Especial de puesta en funcionamiento de las Juntas Municipales de Distrito que inició sus trabajos en 
1991. El citado Reglamento presenta importantes aportaciones como son, entre otras, una regulación exhaustiva de los derechos de los vecinos, la posibilidad de convocar a los representantes de las Asociaciones de Vecinos a las sesiones de las Comisiones Informativas para oír su opinión o recibir sus informaciones y sugerencias, la creación del Registro Municipal de Asociaciones y Colectivos Ciudadanos, la instauración de Juntas Municipales de Distrito, la desconcentración de la Oficina Municipal de Información, etc., y la sustitución en 1995 de la Comisión Mixta por la Comisión Informativa de Participación Ciudadana que, desde 1999, se denomina de Participación Ciudadana y Descentralización Administrativa.

Y podemos también citar, siguiendo la exposición de RUEDA Gómez, el Ayuntamiento de Barcelona que, a través de su polémica Carta Municipal, aprobada por Ley de 30 de diciembre de 1998, como reza su Exposición de Motivos, «profundiza en los mecanismos de participación ciudadana, refuerza la práctica democrática y estimula la cooperación entre el Ayuntamiento y el movimiento asociativo y los agentes sociales, como factor de progreso y cohesión». Como ha señalado un autor, «los cauces de información y participación recogidos en la Carta de Barcelona pueden ser considerados como la máxima expresión de avance en la autoorganización municipal relativa al tema de la participación ciudadana»; y, en opinión de otro autor, de lo que se trata es de ajustar las estructuras locales para que puedan responder a los cuatro desafíos de la participación ciudadana como son la información, la consulta, la codecisión y la cogestión. El texto catalán regula primero lo que denomina «instrumentos de participación ciudadana» como son la audiencia pública por medio de la cual los vecinos proponen determinados acuerdos o reciben información de las actuaciones municipales; la iniciativa ciudadana, mediante la cual los ciudadanos solicitan al Ayuntamiento que lleve a cabo una determinada actividad de interés público y de competencia municipal, y para realizarla los vecinos aportan medios económicos, bienes, derechos o trabajo personal; la iniciativa para aprobar disposiciones de carácter general, es decir, reglamentos; el ejercicio por entidades, organizaciones y asociaciones ciudadanas sin ánimo de lucro de competencias municipales, o la participación, en nombre del Ayuntamiento, en la gestión de servicios o equipamientos cuya titularidad corresponde a otras Administraciones; la consulta ciudadana, a través de la cual se pide la opinión de los vecinos, respetándose el derecho de los consultados a conocer las soluciones alternativas con la máxima información escrita y gráfica posible; la creación del Consejo de Ciudad, integrado por los representantes de las entidades de diversa naturaleza y de vecinos más representativos, como órgano de debate de las grandes cuestiones municipales; y la regulación del Fichero General de Entidades Ciu- 
dadanas para asegurar las buenas relaciones de la Administración municipal con dichas entidades. Y, después de tratar los institutos de participación que se acaban de enumerar, la Carta barcelonesa aborda los derechos de los ciudadanos, entre los que menciona el de ser informados de las actividades municipales, el de acceder a los archivos públicos, y el de utilizar los medios de información general que el Ayuntamiento establezca mediante el uso de cualquiera de las tecnologías al servicio de la comunicación, distinguiéndose, a su vez, entre información pública, información pública individualizada en actuaciones urbanísticas de singular relevancia y otros supuestos establecidos reglamentariamente, y consulta directa a los ciudadanos mediante sistemas telefónicos y telemáticos, de las bases de datos, ficheros y registros que el Ayuntamiento decida abrir al público; el ejercicio del derecho de petición, individual o colectivo, en virtud del cual puede solicitarse que se celebre un debate público previo a la resolución a adoptar; la prestación del servicio de acceso a la información municipal y ciudadana por sistemas telemáticos; el derecho a la información sobre los datos que posea el Ayuntamiento sobre las condiciones ambientales en el término municipal y sobre la contaminación de carácter acústico; y el derecho de los vecinos a ser protegidos por el Ayuntamiento ante las compañías públicas y privadas prestadoras de servicios públicos.

Como puede apreciarse, nos encontramos ante un amplio elenco de posibilidades para ampliar el campo de la participación ciudadana en la vida local, rompiendo de este modo un estado de cosas que, en estos momentos, no se caracteriza precisamente por su originalidad y atracción. El tema debemos valorarlo como clave para el futuro de las Corporaciones Locales, y respecto al mismo nuestros políticos y nuestros ediles tienen mucho que decir, porque ante ellos se presenta un amplio horizonte en orden a mejorar, enriquecer y reforzar las relaciones entre vecinos y autoridades.

2) En segundo lugar, hay que centrar ahora la atención en los estratos directivos de las Corporaciones Locales ya que, en nuestros días, la Nueva Gestión Pública reclama la presencia de auténticos managers o directivos que sepan actuar con criterios modernos a la hora de gestionar cada Corporación Local. Toda la doctrina se muestra de acuerdo en que uno de los grandes déficits de la Administración Local de nuestro país es «la ausencia de recursos humanos suficientemente capacitados y motivados, y especialmente en el nivel directivo» (CAnales Aliende), por lo que, en opinión de este autor, «existe la tentación de cubrir esta carencia acudiendo al clientelismo político, reclutando para ello personal de confianza en detrimento de la profesionalidad que requiere la gestión pública 
local». Por ello, este autor señala que las Entidades Locales «necesitan lo que se ha venido en llamar por la doctrina extranjera managers locales, $o$ directivos locales en nuestra terminología», a los que encomendar básicamente las siguientes tareas: el liderazgo; la comunicación interna y externa; la gestión y aplicación de todos los procesos de reforma y organización; la asunción de la plena responsabilidad a la hora de implementar y poner en práctica las políticas públicas locales y de evaluar sus resultados; y la colaboración y participación en todos los procesos de decisión que se produzcan en el seno de cada Corporación. Por ello, CANales AlIENDE concluye que el manager o directivo local, «como profesional cualificado de la gestión de las políticas públicas locales, aparece como un elemento clave para la implementación de las mismas», tratando de armonizar en la medida de lo posible «las demandas, a veces contradictorias, entre los políticos, los ciudadanos y los empleados públicos de las Entidades Locales».

Abundando en lo que se acaba de decir, parece oportuno traer a colación un documento sobre la gestión de los Ayuntamientos andaluces, publicado en el año 2002 por la Consejería de Gobernación de la Junta de Andalucía, donde se dicen cosas muy interesantes. Según este documento, los partidos políticos no forman a sus Concejales para desarrollar la Nueva Gestión Pública, el modelo «ministerial» que adoptan muchos Ayuntamientos conduce a la división y a la descoordinación, si un político pretende hacer el trabajo de los funcionarios queda atrapado en lo que no sabe y acaba fracasando, hay déficit en el conocimiento de las técnicas de planificación, desarrollo y evaluación, los partidos políticos sólo se preocupan de preparar a los suyos para las contiendas electorales, falta motivación en los miembros de las Corporaciones Locales por lo que se limitan a estar situados en el día a día, no hay planes estratégicos por lo que falta continuidad en la política de recursos humanos o sencillamente ésta no existe, se confunden la función política y la directiva por lo que hay un incremento notable de puestos desempeñados por personal eventual designados por razones de confianza política y no de profesionalidad, etc. Como se ve, todo un repertorio de carencias, defectos y limitaciones que demuestran el camino que nos queda por recorrer hasta disponer de ediles y concejales que sepan estar a la altura de las circunstancias y que traigan a nuestros Ayuntamientos un estilo renovado de gestión y gobierno.

3) En tercer lugar, hay que referirse a los empleados públicos locales. Nadie cuestiona que hoy, tanto en el sector público como en el privado, los recursos humanos, es decir, los funcionarios, los trabajadores locales, constituyen el mejor capital de que disponen las organizaciones; o, como 
dice el Libro Blanco para la Mejora de los Servicios Públicos, del Ministerio de Administraciones Públicas, ellos son el «único capital imprescindible». Estamos ante lo que ahora se denomina «capital humano», que es sin duda el gran factor estratégico de cualquier organización y al que, como no podía ser menos, dedica especial atención la Nueva Gestión Pública que apuesta porque los empleados públicos sean debidamente seleccionados, estén permanente motivados, sean retribuidos con suficiencia, y tengan ante sí opciones de carrera y promoción profesional. Lamentablemente no siempre sucede así, ya que en nuestros Ayuntamientos, especialmente en los de menor población y presupuesto, al igual que sucede en el Estado y las Comunidades Autónomas que, por lo demás, no están libres de culpa en esta materia, se echa en falta una buena política de personal que no se limite a resolver los problemas de cada día, sino que diseñe estrategias que sirvan para el mejor aprovechamiento de los recursos humanos disponibles; y ello no sólo en beneficio de los propios interesados, sino también de la organización a que pertenecen.

No cabe ignorar, por lo demás, el papel relevante que juegan hoy, en medio de dificultades en ocasiones muy serias, los llamados Habilitados Nacionales, es decir, los Secretarios, Interventores y Tesoreros. Se trata de funcionarios cualificados, cuya situación no siempre es cómoda y llevadera, y que en general merecen el respeto y la consideración de todos gracias a la labor que llevan a cabo, careciendo muchas veces de los medios más indispensables para realizar sus funciones sobre todo en municipios medianos y pequeños. Por ello, no se acierta a comprender cuál es la razón última en virtud de la cual los Habilitados Nacionales no acaban de gozar en este país del prestigio tanto social como profesional que se merecen, si comparamos este colectivo funcionarial con otros que sí han obtenido en el seno de la sociedad española una reputación que, a lo mejor, no siempre es acorde con la relevancia de la actividad profesional que tienen encomendada Porque es evidente, de todo punto, que las funciones que desempeñan los Habilitados Nacionales en Ayuntamientos y Diputaciones son muy importantes; $y$, sin embargo, la sociedad española no acaba de asumir esta realidad y de colocar a estos funcionarios locales en la punta de vanguardia de los grupos profesionales y funcionariales, como lógica compensación a la trascendencia de las tareas que llevan a cabo y de las responsabilidades que pesan sobre sus hombros.

En estos momentos, frente a los que desde determinadas posiciones defienden más o menos directamente la supresión de los Habilitados Nacionales, estamos los que creemos en su indispensabilidad y necesidad. Por fortuna, ahora las aguas parecen tranquilas y, en general, salvo mino- 
rías más o menos radicalizadas, se admite y acepta el status jurídico de los Habilitados Nacionales, lo cual no quiere decir que no haya aspectos del mismo que precisen reajustes en cuanto al proceso selectivo, las titulaciones requeridas para el acceso a las oposiciones, y sobre todo la forma de provisión de los puestos de trabajo. Sin embargo, a mi juicio no hay que fiarse demasiado de esta aparente calma en torno a los Habilitados Nacionales, porque, de vez en cuando, si nos atenemos a la experiencia de años pasados, surgen iniciativas que apuntan directamente a la línea de flotación de este colectivo; y como ejemplo reciente tenemos el Proyecto primero denominado de Grandes Ciudades y después de Modernización de la Administración Local y en el que los Habilitados Nacionales ven amenazada su presencia nada menos que en las principales Corporaciones Locales del país.

4) En cuarto lugar, la Nueva Gestión Pública coloca a las Corporaciones Locales ante la exigencia de proyectar y realizar una transformación estructural y orgánica que les permita alinearse con las tendencias más avanzadas en la actualidad. La imagen de una Corporación Local jerarquizada, rígida, centralizada, procedimentalista, ya no tiene defensa alguna, porque las corrientes de los tiempos van en la dirección opuesta, es decir, en la de contar con Corporaciones Locales participativas, flexibles, descentralizadas, permeables al entorno social, despegadas de la rutina legalista y sensibles a las demandas y reivindicaciones ciudadanas.

Dentro de la «revolución» que los tiempos piden a las Administraciones Públicas, y ahora en concreto a la Administración Local, hay un primer aspecto esencial que propugna la Nueva Gestión Pública y es el relativo a la implantación de técnicas del sector privado como son, entre otras, la planificación estratégica, la evaluación del desempeño, la política de calidad de los servicios públicos, la dirección por objetivos, el reconocimiento de la función directiva, los sistemas de control, el aprovechamiento de las nuevas tecnologías, etc. Y un segundo aspecto es el relativo al modo de organizar las estructuras locales, con lo que se está aludiendo a la necesidad de que cada Corporación se autoorganice dentro del marco legal previsto, con arreglo a unas pautas según las cuales su propia organización, su configuración en Concejalías, Departamentos, Áreas, Ramas, etc., ha de tener muy a la vista los principios cada día más aceptados como son los de descentralización, desconcentración, coordinación, cercanía al administrado, delegación de competencias y funciones, etc., a través de los cuales cada Entidad Local sea capaz de responder mejor a las demandas de los vecinos, de readaptarse continuamente a las transformaciones del entorno social, de anticiparse a las necesidades del futuro, de potenciar los 
valores que la diferencien de otras y que sean suyos y que le permitan esgrimir unas peculiaridades y singularidades que definan su propia identidad en medio de un mundo que tiende a hacerlo todo igual. Y es precisamente este último principio, el de la diferenciación, uno de los que deberán intensificar más nuestros pueblos y ciudades a fin de buscar que, de un lado, los vecinos se sientan orgullosos de lo que es propiamente suyo y les diferencia de otras colectividades locales; y de otro, que los foráneos se sientan atraídos por conocer y vivir lo que sólo esta o aquella localidad les pueda ofrecer en cuanto a turismo, paisaje, ocio, gastronomía, folklore, etc.

5) Como complemento del punto anterior, en quinto lugar, y al hilo de la reforma local aprobada recientemente por el Consejo de Ministros, y que afecta básicamente a las grandes ciudades, hoy más que nunca está abierto el tema del tradicional uniformismo de nuestro Régimen Local. A estas alturas, dada la situación política y social que vivimos en nuestro país, se impone inexorablemente acabar con el uniformismo local, de modo y manera que se arbitren medidas legales para que las Corporaciones Locales, y básicamente en este caso los Ayuntamientos, se puedan configurar libremente, dándose a sí mismos una configuración acorde con sus características y las del contexto en el que están insertos. Quizás, con alguna frecuencia, a los Ayuntamientos les falta imaginación para diseñar un modelo organizativo más ajustado a su realidad socioeconómica, pero también hay que reconocer que el legislador estatal y autonómico tampoco se muestran demasiado proclives a romper el uniformismo local y a fomentar la variedad y la diversidad estructural en el ámbito local.

6) Finalmente, en sexto lugar, hay que citar un plano de la vida local que, aunque a algunos les pueda parecer equivocado o extraño, sin embargo en mi opinión cara al porvenir habrá que tener muy en cuenta. Me estoy refiriendo a lo que se ha dado en llamar la «repolitización» de la vida local (Quim BRUgué y Ricard Gomá). En este orden de cosas, está bien que atendamos a los requerimientos de la Nueva Gestión Pública y la aceptemos en sus postulados y planteamientos, pero la revitalización de nuestra Administración Local pasa además porque traigamos hasta ella los aires frescos de la Política con mayúscula. Por eso, hay que hablar de la «repolitización» de nuestra vida local que es tanto como decir que en ésta no puede faltar la dinámica política, que no puede estar ausente la confrontación ideológica, que no podemos privar a los vecinos de elegir entre varias alternativas de partido o de grupo.

Decimos todo esto, porque ciertamente hay un peligro al acecho como es el de que, si nos dejamos llevar por una Administración Local muy tec- 
nificada y muy burocratizada, entonces estaremos atacando las raíces mismas de la democracia local. Y si entregamos las Casas Consistoriales a tecnócratas sin alma, a funcionarios engreídos, a gestores insensibles, contribuiremos a alejar a los vecinos y a distanciarlos de los que deben ser sus mejores valedores y sus más fieles protectores. Para oponerse a esta situación de todo punto indeseable, el mejor antídoto es recuperar la política en el sentido más noble de la palabra y dar entrada en el escenario político no sólo a los partidos, cuya crisis es clara en cuanto a ser los únicos canalizadores de las inquietudes ciudadanas, sino a otros grupos que sean capaces de dinamizar la democracia local y de aparecer como portavoces de segmentos sociales más o menos significados.

Como se comprenderá por estas últimas palabras, estamos tocando el corazón de la problemática política actual en su vertiente de la representación y la elección de los representantes de los ciudadanos ante las instituciones públicas. ¿Dónde radica la solución del problema apuntado? Posiblemente en un replanteamiento en profundidad del papel de los partidos políticos, teniendo en cuenta que cada vez se hacen más presentes en la escena pública otros medios de participación, que van desde el creciente peso específico de los medios de comunicación social hasta la intervención de nuevas formas de asociación y nuevos movimientos sociales, que se adivinan como actores muy influyentes en la vida política y social. Estos nuevos actores, dice Edurne URIARTE, «se sitúan fuera de lo que podríamos considerar política tradicional», que es la que llevan a cabo «los partidos políticos y las instituciones centrales de la democracia representativa como las elecciones y el Parlamento»; y lo que importa subrayar es que «reflejan el ascenso de los valores postmaterialistas, es decir, los valores de la autonomía, de la calidad de vida, de la autoexpresión y de la participación»y, sobre todo, «están impulsados por las nuevas generaciones surgidas de las décadas de bienestar y paz de los países occidentales en los que los jóvenes desarrollan nuevas reivindicaciones, una vez que la democracia representativa y el bienestar económico están asegurados». Por tanto, es preciso tener muy en cuenta ambas actitudes, a la hora de intentar dinamizar la vida local en sus diversos aspectos y manifestaciones, ya que conjuntamente contribuirán a establecer una convivencia no sólo rodeada de comodidades materiales, sino también acompañada de nuevos valores, vivencias y aspiraciones.

En todo caso, cabe concluir que la «repolitización» de nuestra vida local conduce, de un lado, al replanteamiento pero, en ningún caso, a la exclusión de la acción de los partidos políticos y, de otro, a la aceptación del protagonismo creciente y acelerado de otro cauces de participación 
pública. Todo ello sin perjuicio de que la Nueva Gestión Pública se intensifique y acepte por las Corporaciones Locales, a fin de que asuman la renovación y el cambio, sin llegar a caer en un burocratismo exagerado o en un gerencialismo distante que sofoque o margine las inquietudes y propuestas ciudadanas y populares.

\section{LAS COMUNIDADES DE VECINOS}

Y ya, en el tramo final del presente trabajo, interesa dedicar un breve espacio de tiempo a reflexionar sobre la manera en que la Nueva Gestión Pública reclama un cambio de actitud y de talante en nuestras Comunidades de Vecinos. Porque es cierto que si, ante lo que significa la Nueva Gestión Pública, hay muchas cosas que cambiar en las Corporaciones Locales, también lo es que idéntico cambio ha de producirse a nivel de los ciudadanos, de los contribuyentes, de los vecinos, de los interesados, de los administrados en general.

Normalmente los administrativistas y los politólogos centran su atención en la Administración Pública, a la que sitúan en su punto de mira para que se actualice y se modernice, lo cual está muy bien y es de todo punto necesario. Sin embargo, y es el extremo que me gustaría analizar brevemente, no podemos dejar en la penumbra al otro sujeto de la relación pública, como es hablando en términos genéricos el vecino; porque, en la actualidad, ya no estamos ante unos poderes públicos que pueden gobernar desde el autoritarismo o la soledad, sino que, por el contrario, han de contar con los ciudadanos ya que hoy el ejercicio del poder y el manejo de los resortes legales han de hacerse desde posturas de consenso, de negociación, de participación, de diálogo. Ya pasó la época en que el Concejal o el funcionario eran los únicos que monopolizaban la decisión de lo que era el interés general e imponían sus criterios de manera imperativa y absoluta. Ahora la sociedad civil está preconizada a compartir con los poderes públicos esta difícil misión de decidir lo que es beneficioso para la generalidad y lo que es conveniente para la mayoría. En consecuencia, la Administración no puede encerrarse en su torre de marfil, creyendo que puede hacer lo que quiera fiada en que tiene tras de sí la fuerza de la ley y, llegado el caso, la utilización de medios coercitivos y de ejecución forzosa. Hoy, más bien, cualquier Administración tiene que abrirse a la calle, desplegar sus posibilidades de convencimiento y atracción, valorar los requerimientos del vecindario, para que, de común acuerdo, se dé una perfecta sintonía entre gestores y ciudadanos, sin la cual es imposible gobernar. 
Por tanto, en este doble protagonismo Ayuntamiento-Comunidad de Vecinos, hoy más que nunca son éstos los que han aportar su granito de arena y saber estar a la altura de las circunstancias, a fin de que no suceda que, por la falta de colaboración o incluso por una hostilidad más o menos encubierta, los proyectos e iniciativas de los gestores locales se ven frenados, cuando no claramente torpedeados o destruidos. Muchas veces criticamos, y con razón, a nuestros políticos locales, pero conviene no olvidar que, muchas veces, somos nosotros, los destinatarios de sus decisiones, los que no sabemos cumplir nuestros deberes cívicos y los que no queremos asumir nuestras responsabilidades. Por eso, utilizando la terminología de Siedentof, hemos de apelar a instalar en nuestras conciencias lo que este autor denomina «ciudadanía activa», es decir, un comportamiento que lejos del desinterés por lo público y lo colectivo apueste por un compromiso dinámico y creciente en la resolución de los problemas que, siendo de cada uno de nosotros, también son de todos.

En nuestro país, es tradicional que todos esgrimamos nuestros derechos pero que olvidemos nuestras obligaciones. Achacamos los males de la sociedad única y exclusivamente a los políticos de turno y no nos percatamos de que parte de culpa de que las calles estén sucias, los servicios públicos no funcionen como Dios manda, la convivencia a nivel local se torne conflictiva y turbia, la tenemos nosotros; y sólo si nosotros, desde posiciones de disponibilidad y entendimiento, nos comportamos correctamente, las cuestiones pueden empezarse a resolver y a entrar en vías de solución.

Hoy el político, el gestor estatal, autonómico o local, está atado de pies y manos si no encuentra adhesión a sus ofertas y si no consigue el respaldo mayoritario de los ciudadanos. Ésta es, por lo demás, la razón de que, en la actualidad, cuando se pretende sacar adelante una iniciativa gubernamental (sea una modificación del Impuesto sobre la Renta de las Personas Físicas, la prohibición de fumar, la lucha contra el ruido, una campaña de limpieza, etc.), lo primero que se hace es lanzar una masiva campaña de mentalización o concienciación de los ciudadanos, cuando no se apela a los sondeos y encuestas para detectar el grado de consenso o rechazo con que tal o cual medida será recibida por quienes van a ser sus destinatarios finales. Resulta, en consecuencia, extraño y paradójico que hoy los gobernantes gocen de amplios poderes para «imponer» sus ideas y, sin embargo, necesiten más que nunca el consentimiento de sus súbditos a fin de que sus proposiciones e iniciativas no choquen contra el abandono popular o, lo que es casi peor, naufraguen en medio de la pasividad y la indiferencia.

La pregunta que tenemos que hacernos es cómo pueden hoy los vecinos alinearse con sus Ayuntamientos para que los objetivos de la Nueva Ges- 
tión Pública sean realizables y contribuyan al bienestar generalizado de todos los afectados. El punto de partida no puede ser otro, como escribe Manuel VILloRia, que el hecho de que el vecino consumidor, usuario, contribuyente, interesado, es, en definitiva, el propietario y el responsable de los servicios municipales. A partir de este postulado, que define la necesaria vinculación entre el Ayuntamiento y la sociedad civil, podemos ya esbozar las siguientes vías o posibilidades de interrelación AyuntamientoComunidad de Vecinos:

1) En primer lugar, los vecinos han de afinar y poner a punto sus instrumentos de control y fiscalización de lo que hacen sus gestores municipales. Uno de los principales valores de la democracia es el control y sin el cual aquélla no existe o tan sólo aparece nominalmente. Por tanto, los vecinos han de organizarse colectivamente y aunar sus esfuerzos a fin de lograr que su Ayuntamiento se sienta controlado y vigilado; y que sepan sus integrantes que si actúan fuera de la legalidad, van a encontrarse con la oposición organizada y rigurosa de los vecinos y con la crítica de los medios de comunicación social.

2) En segundo lugar, las comunidades de vecinos tienen que implicarse directamente en las tareas colectivas pilotadas por el Ayuntamiento y ser solícitas a las llamadas que éste les haga para la colaboración. Aquí entra todo el tema, ya desarrollado, de la participación y que está llamado a tener una importancia creciente en el futuro. Desde esta perspectiva los vecinos deben colaborar con «su» Ayuntamiento y, a su vez, éste debe contar con «sus» vecinos para reclamarles sugerencias, innovaciones, cambios, rectificaciones, etc., que se puedan tener a la vista para mejorar la gobernabilidad y la calidad de vida del municipio.

Aquí late todo el problema ya esbozado de si los partidos políticos deben ser las únicos mediadores entre el poder local y los ciudadanos ya que, en el horizonte, emergen nuevos actores en la escena pública como son los medios de comunicación social, las organizaciones no gubernamentales, las agrupaciones más diversas (desde las de comerciantes hasta las de colectivos marginados, pasando por las de contribuyentes, usuarios de servicios públicos, etc.). A este respecto, posiblemente debamos aceptar la tesis de Jordi BoRJA, especialista catalán en materias de descentralización y participación ciudadana, de que los partidos políticos son un instrumento de participación y las elecciones el momento culminante de dicha participación; pero, en nuestros días, ni los partidos políticos tienen el monopolio de la participación popular ni ésta mucho menos puede reducirse al momento de las elecciones. El desarrollo de la verdadera democracia va vinculado hoy también al desarrollo y potenciación de 
otras formas de participación, y esta afirmación es más cierta en los municipios que en ninguna otra parte del Estado, tal como ya expresé con anterioridad.

3) En tercer lugar, es necesario que los vecinos sean conscientes de que el llamado Estado del Bienestar no es un pozo sin fondo, o hablando más gráficamente una máquina de hacer dinero para atender y satisfacer todo lo que se pida. En estos días la prensa está dedicando especial atención a «la crisis del Estado del Bienestar» en países opulentos y muy desarrollados de Europa. Lo que estamos presenciando, con referencia concreta al tema de las pensiones, es lo que se ha denominado «sobrecarga de reivindicaciones» por parte de los ciudadanos que consideran que el Estado es todopoderoso y sus recursos inagotables. Planteadas así las cosas, las consecuencias son en todo caso arriesgadas y peligrosas: para el Estado, porque se genera la sensación de impotencia e incapacidad para atender las peticiones de los ciudadanos; y para éstos, porque se acaban rebelando, más o menos claramente, contra lo que consideran un engaño, una frustración, una deserción por parte de los poderes públicos.

Tal como está la situación, y por mucho que prometan los partidos políticos en las campañas electorales o por mucho que inciten a la demanda desmesurada de bienes y servicios ciertos medios de comunicación social, el hombre común y corriente, el vecino de a pie, debe ser consciente de que no puede pedir «todo» lo que le antoje, de que no puede descolgarse con reclamaciones irrealizables e inatendibles, de que ha de moderar sus exigencias en razón de los medios disponibles para atenderlas. Y es aquí donde podemos ubicar lo que podríamos llamar el «ciudadano sistemáticamente reivindicativo» que es aquel que, en cuanto se le presenta la ocasión, lo pide todo a cualquier precio y sin limitaciones de ningún género, sin importarle para nada que la organización o institución a la que se dirige nunca podrá complacerle aunque quisiera, por carecer de los medios necesarios para ello. Porque otra cosa bien distinta, y conviene dejarlo bien claro, es el denominado por los sociólogos y politólogos el «ciudadano sofisticado» que es aquel que, bien informado y buen conocedor de las leyes, se interesa por los asuntos públicos y en base a su buena formación se muestra cada vez más crítico con el poder al que reclama, desde sus posiciones de conocimiento de los hechos, un comportamiento adecuado y ético.

4) En cuanto lugar, dado que vivimos en una sociedad cada vez más compleja, multicultural y heterogénea, en la que los grupos sociales se fragmentan y dividen, de modo que cada uno trata de actuar por su cuenta y riesgo, se hace indispensable que la comunidad vecinal asuma y mane- 
je razonablemente esta complejidad y fragmentación que advertimos en los barrios, distritos, calles, zonas de recreo u ocio, cada una de las cuales tiene su propio catálogo de carencias y de peticiones ante el Ayuntamiento. Quiere decirse, pues, que los ciudadanos cada vez formulan demandas más singularizadas y específicas y que, por tanto, no pueden tener una respuesta común o estandarizada, como ya señaló en 1989 un documento de la OCDE. Este fenómeno acelerado de la complejidad social, de la existencia de un tejido social muy compartimentado, sin duda dificulta la gobernabilidad a escala local, ya que el Ayuntamiento no puede actuar globalmente y de igual manera para todos. De ahí que, hoy, sea más difícil gobernar que antes, puesto que la sociedad es más compleja y se diversifica en grupos y colectivos de muy variada índole, al tiempo que los ciudadanos están mejor informados que antes. Esta nueva situación tiene que ser conocida y respetada por los vecinos que han de ser conscientes de que sus demandas no son las únicas; y de que, en definitiva, de lo que se trata es de armonizar los intereses en juego y de combinar racionalmente las peticiones que se formulen, estableciendo entre ellas una lógica jerarquía y una necesaria priorización en base a datos objetivos y neutrales que definan su urgencia en unos casos y su trascendencia social en otros.

5) En quinto y último lugar, la comunidad vecinal tiene que fomentar cada vez más escrupulosamente el cumplimiento de nuevos deberes y compromisos públicos de sus componentes, porque, en los tiempos que corren, cuando el hombre contemporáneo apuesta por nuevos valores, que unos han denominado «valores postmaterialistas» y otros «derechos difusos», como son la calidad de vida, la defensa del medio ambiente, la protección de la naturaleza, el amor por la cultura y la ciencia, el derecho a la salud, etc., se requiere que todo vecino eleve su nivel de conducta colectiva y solidaria, depurando sus hábitos de convivencia con los demás y al lado de los demás, de tal modo que, entre todos, contribuyan a hacer más grata las relaciones vecinales. Ello supone que la comunidad vecinal debe aumentar su campo de mira y ha de prestar atención progresiva hacia nuevas metas de solidaridad, de calidad de vida, de cultivo de virtudes sociales y comunitarias, de tal manera que se asegure para todos los habitantes del municipio una forma de convivencia más sólida, satisfactoria y gratificante.

\section{BIBLIOGRAFÍA UTILIZADA}

Bañón, R. y Carrill, E. (comps.), La Nueva Administración Pública, Alianza Editorial, Madrid, 1997. 
BauzÁ Martorell, F. J., Aproximación a la Ciencia de la Administración, Madrid, 1999.

BORJA, J., Descentralización y participación ciudadana, Instituto de Estudios de Administración Local, Madrid, 1987.

Canales Aliende, J. M., «La reorientación y la revitalización de los gobiernos locales en España», Revista de Gestión y Análisis de Políticas Públicas, n. ${ }^{\circ}$ 10, setiembre-diciembre 1997.

Canales Aliende, J. M., Lecciones de Administración y de Gestión Públi$c a$, Publicaciones de la Universidad de Alicante, 2002.

BRugué, Q. y Gomá, R. (coords.), Gobiernos locales y políticas públicas, Editorial Ariel, Barcelona, 1998.

Dahrendorf, R., Después de la democracia, Crítica, Barcelona, 2002.

DíAz, A., «Sistema municipal de gestión de calidad. La aplicación de los modelos de calidad a la gestión pública», Revista de Gestión y Análisis de Políticas Públicas, n. ${ }^{\circ}$ 3, mayo-agosto 1995.

Donolo, C., ¿Cómo gobernar mañana?, Galaxia Gutemberg. Círculos de Lectores, Madrid, 1999.

Dunleavy, P. y Hood, C., «De la Administración Pública tradicional a la nueva gestión pública. Ensayo sobre la experiencia modernizadora de diversos países desarrollados», Revista de Gestión y Análisis de Políticas Públicas, n. ${ }^{\circ}$ 3, mayo-agosto 1995.

Metcalfe, L. y Richards, S., La modernización de la gestión pública, Instituto Nacional de Administración Pública, Madrid, 1989.

Ministerio de Administraciones Públicas, Libro blanco para la mejora de los servicios públicos, Madrid, 2000.

«Nota sobre la escasa formación de los ediles que impide una gestión moderna y eficaz», Revista de Estudios Locales, junio 2002.

OCDE, La Administración al servicio del público, Ministerio de Administraciones Públicas, Madrid, 1987.

OCDE, Flexibilidad en la gestión de personal en la Administración Públi$c a$, Instituto Nacional de Administración Pública. OCDE, Madrid, 1995. 
OCDE, La transformación de la gestión pública. Las reformas de los países de la OCDE, Ministerio de Administraciones Públicas. Ministerio de la Presidencia. Boletín Oficial del Estado, Madrid, 1997.

Olías de Lima, B., La Nueva Gestión Pública, Prentice Hall, Madrid, 2001.

Pineda Nebot, C., «Gobiernos locales: participación ciudadana en el proceso presupuestario», Revista de Gestión y Análisis de Políticas Públicas, n. 22 , setiembre-diciembre 2001.

Rueda Gómez, J. M., «La participación ciudadana en la vida local. Especial referencia al Ayuntamiento de Granada», El Consultor de los Ayuntamientos, n. $^{\circ} 18,30$ setiembre 2002.

Siedentof, L., La democracia en Europa, Siglo Veintiuno de España Editores, Barcelona, 2001.

Subirats i Humet, J., Análisis de políticas públicas y eficacia de la Administración, Instituto Nacional de Administración Pública, Madrid, 1989.

Subirats i Humet, J., «Gobierno local y políticas públicas. Apuntes en la España de los noventa», Revista Valenciana d'Estudis Autonomics, n. ${ }^{\circ}$ 15, febrero-mayo 1996.

Termes Anglés, F., «Principios que inspiran la reforma del sector público alrededor del mundo», en La reforma del sector público. Experiencias y tendencias en el mundo actual, Sindicatura de Comptes de Catalunya, Barcelona, 2001.

Uriarte, E., Introducción a la Ciencia Política, Tecnos, Madrid, 2002. 